\title{
In-vitro Antimicrobial Activity and Phytochemical Screening of Fritillaria delavayi
}

\author{
Bijaya L. Maharjan, Hari K. Devkota and Bikash Baral \\ Nepal Academy of Science and Technology (NAST), Khumaltar, Lalitpur \\ e-mail: utpalbodhi@gmail.com
}

\begin{abstract}
Fritillaria delavayi Franch is one of the medicinal plants used in traditional medical system for ailment of various diseases. But scientific study of the plant has been less carried out for which the study was conducted for validation of prevailing medical practice. The soxhlet extraction of the bulbs of plant were conducted in various solvents (hexane, chloroform, ethyl acetate, methanol and water) differing in polarity. Maximum yield (6.79\%) was obtained in aqueous fraction and lowest (0.14\%) in ethyl acetate fraction. The phytochemical screening of extracts revealed the presence of volatile oil, glycosides, sterol and triterpenes, polyoses, saponins, reducing compounds, quinones, flavonic glycosides and coumarins. In antimicrobial assay conducted by agar well diffusion method, chloroform fraction was found to be more effective towards bacterial and fungal pathogens tested, followed by ethyl acetate and methanol fraction. The hexane and aqueous fractions were found to be least effective against all the tested pathogens. Among the bacterial pathogens, maximum inhibition zone was depicted against Klebsiella pneumoniae (22 $\mathrm{mm}$ ) by chloroform extracts while among the fungal pathogens, greatest inhibition activity was observed against Fusarium moniliforme $(19 \mathrm{~mm})$. The antimicrobial activity of extracts suggested potential use of the plant in treatment of various diseases.
\end{abstract}

Key words: antibacterial, antifungal, extract

\section{Introduction}

Nature stands a golden mark and provides the storehouse of remedies to cure all ailments of mankind. Herbs have always been the principal form of medicine in Nepal and presently they are becoming popular throughout the world as people strive to stay healthy in the face of chronic stress and pollution and to treat illness with medicines that work in count with the body's own defense. There is a widespread belief that green medicines are healthier and safer than synthetic ones (Sindhia \& Bairwa 2010). The increasing prevalence of multidrug resistant strains of bacteria and the recent appearance of strains with reduced susceptibility to antibiotic raises the specter of untreatable bacterial infections and adds urgency to the search for new infection-fighting strategies (Sieradski et al. 1999)

In traditional medicine, there are many natural crude drugs that have the potential to treat many diseases 
and disorders and one of them is Fritiuaria. delavayi Franch. Fritillaria is a genus of about 1000 species of bulbous plants belonging to the family Liliaceae. It is a perennial temperate herb that grows in mountain slopes and sub-alpine meadows, usually on open, stony and moist hill sides. F. delavayi is a rare species found at an altitude around $3800-4700 \mathrm{~m}$. The bulbs look normal in size but are considerably larger as compared to the plant aerial part (Suo 1898). In the West, Fritillaria is most commonly regarded as an ornamental garden plant. It is traditionally valued as an herbal remedy in Nepal and China. This species is exported to China and India from Nepal since the few years because of its high medicinal properties (Thomson 2007).

Fritillaria affects the heart and lung meridians or energy pathways in the body and is used primarily to treat various lung diseases, including asthma, bronchitis, tuberculosis and coughs of any type. It is also used as a lymphatic decongestant to reduce swellings, nodules, fibrocystic breasts, goiter and swollen lymph glands. Previous research reveals that it is used for treatment of nervous system, prolonged decrease in blood pressure, stimulation of the heart muscle and dysfunction of breathing (Erika \& Rebecca 2005).

Plant contains phytochemicals to protect itself. But recent researches demonstrate that many phytochemicals can protect human and plants diseases (Lata \& Dubey 2010). Compounds theorized to be responsible for activity includes several bioactive isosteroidal alkaloids (verticine, verticinone, isoverticine, imperialine, hupe henine, ebeiedine, ebeienine and ebeiedinone) and 2 nucleosides (thymidine and adenosine) (Erika \& Rebecca 2005).

Very less pharmacological and antimicrobial study has been reported on F. delavayi, for which the study was designed to establish scientific basis for some of its therapeutic properties in traditional use. This investigation encourages for further findings of medicinal plants. Hence, the study deals with the phytochemical screening and antimicrobial assay that helps in scientific evaluation of bioactive compounds and may prove beneficial for mankind.

\section{Methodology Collection of samples}

The bulbs of $F$. delavayi were collected from Manaslu conservation area during spring. They were shade dried and pulverized in powder form. Plants have been identified with the help of local personnel, herbarium specimens and different available literature.

\section{Preparation of extract}

The powdered sample were extracted by soxhlet extraction method using hexane, chloroform, ethyl acetate, methanol and water as solvent in the order of increasing polarity. Then, solvents from extracts were removed under reduced pressure with the aid of rotary vaccum evaporator. The yield of extracts was determined as

Yield $(\%)=(w t$. of extract $/$ wt. of sample $) \times 100$

\section{Phytochemical screening}

The extracts obtained in various solvents were screened for the presence of different chemical compounds according to defined protocol (Harborne 1998).

\section{Antimicrobial assay}

For antimicrobial assay, all fractions of extracts were dissolved in dimethyl sulphooxide (DMSO) such that final concentration of solution was $100 \mathrm{mg} / \mathrm{ml}$. The invitro growth inhibitory activity of different fractions of extracts against the bacterial and fungal strains was conducted by agar well diffusion method (Dingle $e t$ al. 1953). For the analysis, 10 different human pathogenic bacterial strains and 5 different plant pathogenic fungal strains were used. The bacterial strains used were Enterococcus sp., Pseudomonas aeruginosa, Klebsiella pneumoniae, Proteus 
Bijaya L. Maharjan et al./In-vitro Antimicrobial......

mirabilis, Staphylococcus aureus, Salmonella typhi, Salmonella paratyphi, Bacillus subtilis, Schigella sp. and Escherichia coli that were obtained from National Public Health Laboratory, Teku, Kathmandu, Nepal. The fungal strains include Fusarium oxysporum, F. proliferatum, F. eridiforme, F. moniliforme and Exserohilum sp. that were obtained from Nepal Agricultural and Research Council, Khumaltar, Lalitpur, Nepal.

The antibacterial test was done on Mueller Hinton agar medium (MHA) by spread plate technique and maintaining inoculums size as compared to Mac Farland 0.5. Similarly, for antifungal assay potato dextrose agar (PDA) medium was used and inoculum size was maintained to $1 \times 10^{6}-5 \times 10^{6}$ spores $/ \mathrm{ml}$ (Aberkene et al. 2002). Antimicrobial test was detected by measurement of zone of inhibition (ZOI) produced around the well inoculated with extracts after incubation $\left(37^{\circ} \mathrm{C}\right.$ for $24 \mathrm{hr}$ for bacterial strains and $27^{\circ} \mathrm{C}$ for 5 days for fungal strains). To rule out activity of the solvent used in preparation of test solutions, a control was also maintained simultaneously. The entire assay was performed in triplicates.

\section{Results and Discussion}

The extraction of $F$. delavayi in different solvents showed maximum yield in aqueous fraction while there was a lowest yield in ethyl acetate fraction. Screening of different extract fractions revealed the presence of volatile oil, glycosides, sterol and triterpenes, polyoses, saponins, reducing compounds, quinones, flavonic glycosides and coumarins (Table 1).

The antimicrobial assay depicted chloroform and ethyl acetate fractions to be more effective towards bacterial and fungal pathogens tested, followed by methanol fraction. Hexane and aqueous fractions were found to be least effective against all the tested pathogens. The aqueous fraction showed inhibition zone against one bacterial and two fungal pathogens while hexane fraction produced inhibition zone against only one fungal pathogen.
All the pathogens tested were inhibited by two or more fractions of extracts except $S$. paratyphi that was found to be resistant towards all extracts used for antimicrobial assay.

Table 1. Qualitative phytochemical screening of different extracts of $F$. delavayi

\begin{tabular}{l|c}
\hline Phytochemicals & Occurrence \\
\hline Volatile oil & + \\
Sterol and triterpenes & - \\
Carotenoids & - \\
Fatty acids & + \\
Polyoses & + \\
Saponins & - \\
Polyphenols & + \\
Reducing compound & - \\
Alkaloids & + \\
Glycosides & + \\
Quinones & - \\
Anthocyanosides & - \\
Anthracyanosides & + \\
Flavonic glycosides & + \\
Coumarins & + \\
\hline
\end{tabular}

Note: (+): presence; (-): absence



Fig. 1. Yield percentage of the different extract fractions of F. delavayi 
Nepal Journal of Science and Technology 12 (2011) 85-90

Table 2. In-vitro growth of inhibition zones of some bacteria by crude extracts of $F$. delavayi

\begin{tabular}{l|c|c|c|c|c}
\hline \multirow{2}{*}{ Bacterial strains } & \multicolumn{5}{c}{ Zone of inhibition given by the different extracts (mm) } \\
\cline { 2 - 6 } & \multicolumn{5}{c}{ Diameter of well: $\mathbf{6 ~ m m}$} \\
\cline { 2 - 6 } & Hexane & Chloroform & Ethyl acetate & Methanol & Aqueous \\
\hline Enterococcus sp. & - & 16 & 22 & 10 & - \\
P. aeruginosa & - & 12 & 9 & 14 & - \\
K. pneumoniae & - & 22 & 14 & 9 & - \\
P. mirabilis & - & 16 & 11 & 11 & - \\
S. aureus & - & 9 & - & - & - \\
S. paratyphi & - & - & 9 & - & - \\
S. typhi & - & 14 & 14 & 9 & - \\
B. subtilis & - & 18 & 15 & 14 & - \\
Schigella sp. & - & 13 & 16 & - \\
E. coli & - & 12 & & - \\
\hline
\end{tabular}

"-": Absence

Values indicate the means of three replicates

Table 3. In-vitro growth of inhibition zones of some fungi by crude extracts of F. delavayi

\begin{tabular}{|c|c|c|c|c|c|}
\hline \multirow[t]{3}{*}{ Fungal strains } & \multicolumn{5}{|c|}{ Zone of inhibition given by the different extracts } \\
\hline & \multicolumn{5}{|c|}{ Diameter of well: $6 \mathrm{~mm}$} \\
\hline & Hexane & Chloroform & Ethyl acetate & Methanol & Aqueous \\
\hline F. proliferatum & - & 18 & 9 & - & - \\
\hline F. oxysporum & - & 16 & 11 & 9 & - \\
\hline F. erdiforme & - & 12 & 9 & - & - \\
\hline F. moniliforme & - & 19 & 8 & 7 & 9 \\
\hline Exserohilum sp. & 8 & 12 & - & - & 13 \\
\hline
\end{tabular}

"-": absence

Values indicate the means of three replicates

\section{Discussion}

The use of herbs for medicinal purpose is a universal phenomenon. Every culture and civilization on earth, through written or oral tradition, has relied on vast variety of natural chemistries found in plants for their therapeutic properties. All drugs from the plant are substances with a particular therapeutic action extracted from plants. Plant substances continue to serve as viable source of drugs for the world population and several plant-based drugs are in extensive clinical use (Rosa \& Rao 2000).

The curative properties of plants are perhaps due to the presence of various secondary metabolites which are non nutritive plant compounds. These classes (such as alkaloids, tannins, anthraquinones and flavonoids) of compounds are known to have curative activity against several pathogens and therefore could suggest the use of it traditionally for treatment of various illnesses (Usman \& Osuji 2007).

The difference in antimicrobial activity of different fractions of extracts may be due to difference in solubility of bioactive compounds in various solvents. Also the microbes vary in their cell wall composition. The mode of action of different bioactive compounds varies which depict the ability of these compounds to kill or inhibit microbes.

According to Gonzalez et al (1994), optimal effectiveness of a medicinal plant may not be due to 
Bijaya L. Maharjan et al./In-vitro Antimicrobial......

one main active constituent, but to the combined action of different compounds originally present in the plant.

The chloroform extract was found to be greatly effective in inhibiting growth of the tested bacterial and fungal pathogens, followed by ethyl acetate fraction. This suggests that the compounds responsible for antibacterial and antifungal effects are soluble in those solvents. Further research can be conducted to isolate other potential activities of the plant such as antioxidant property that will finally pave the way for production of bioactive prophylactic agents.

\section{References}

Aberkene, A., M. Cuenca-Estrella., A. Gomez-Lopez., E. Petrikkou., E. Mellado., A. Monzon., J. L. RodriguezTudela and the Eurofung Network. 2002. Comparative evaluation of two different methods of inoculum preparation for antifungal susceptibility testing of filamentous fungi. Journal of Antimicrobial Chemotherapy 50(5): 719-722.

Dingle, J., W. W. Red., and G. L. Solomons. 1953. The enzymatic degradation of pectin and other polysaccharides, applications of the cup assay method to the estimation of enzyme. Journal of Science, Food and Agriculture 40: 149-153.

Erika, L and J. F. Rebecca. 2005. Gale encyclopedia of public health. Gale Cengage Learning.
Gonzalez, A., G. Maujir., I. Bazzocchi., I. L. Correa and M. D. Gupta. 1994. Screening of antimicrobial and cytotoxic activities of Panamanian plants. Phytomedicine 1: 149-153.

Harborne, J. B. 1998. Phytochemical methods. A guide to modern techniques of plant analysis. $3^{\text {rd }}$ ed. Chapman and Hall Int. New York.

Lata, N. and V. Dubey. 2010. Preliminary phytochemical screening of Eichhornia crassipes: the world's worst aquatic weed. J. of Pharmacy Research 3(6): 1240-1242.

Rosa, G. and P. S. Rao. 2000. Anticancer compounds from tissue cultures of medicinal plant. J. of Herbs and Spices Med. Plants 7: 71-102.

Sieradski, K., R. B. Roberts., S. W. Haber and A. Tomasz. 1999. The development of vancomycin resistance in a patience with methicillin resistant Staphylococcus aureus infection. N. Engl. J. Med. 340: 517-523.

Sindhia, V. R. and R. Bairwa. 2010. Plant review: Butea monosperma. Int. J. of Pharmaceutical and Clinical Research 2(2): 90-94.

Suo, S. B. M. 1898. Flora of China. 24: 132

www.efloras.org.

Thomson, G. E. 2007. A report for the rural industries research and development corporation. The health benefits of traditional Chinese plant medicines: weighing the scientific evidence. Australian Government.

Usman, H. and J. C. Osuji. 2007. Phytochemical and invitro antimicrobial assay of the leaf extract of Newbouldia leavis. Afr. J. Trad. CAM 4(4): 476-480.

http://rareplants.co.uk/ product.asp?strParents $=\& \mathrm{CATID}=454 \& \mathrm{IPID}=1149$

http://www.altmd.com/Articles/Fritillaria-Encycolpediaof-Alternative-medicine. 
Nepal Journal of Science and Technology 12 (2011) 85-90 